\title{
Mechanical circulatory support. An expert opinion of the Association of Intensive Cardiac Care and the Association of Cardiovascular Interventions of the Polish Cardiac Society
}

Agnieszka Tycińska ${ }^{1 *}$, Marek Grygier ${ }^{2 *}$, Jan Biegus ${ }^{3}$, Tomasz_Czarnik4 ${ }^{4}$, Maciej Dąbrowski ${ }^{5}$, Rafał Depukat ${ }^{6}$, Marek Gierlotka ${ }^{7}$, Monika Gil' ${ }^{1}$, Michał Hawranek ${ }^{8}$, Tomasz Hirnle ${ }^{9}$, Marek Jemielity ${ }^{10}$, Bogusław Kapelak ${ }^{11,12}$, Paweł Kralisz ${ }^{13}$, Wiktor Kuliczkowski ${ }^{3}$, Mariusz Kuśmierczyk ${ }^{14}$, Marcin Ligowski ${ }^{10}$, Paulina Łopatowska ${ }^{1}$, Mateusz Puślecki ${ }^{10,15}$, Andrzej Świątkowski ${ }^{16}$, Przemysław Trzeciak ${ }^{8}$, Barbara Zawiślak ${ }^{17}$, Michał Zembala ${ }^{18,19}$, Robert Zymliński

Reviewers: Wojciech Wojakowski ${ }^{19,20}$, Marek A Deja ${ }^{20,21}$

'Department of Cardiology, Medical University of Bialystok, Białystok, Poland

${ }_{2}^{2} 1^{\text {st }}$ Department of Cardiology, Poznan University of Medical Sciences, Poznań, Poland

${ }^{3}$ Institute of Heart Diseases, Wroclaw Medical University, Wrocław, Poland

${ }^{4}$ Department of Anesthesiology and Intensive Care, Institute of Medical Sciences, University of Opole, Opole, Poland

${ }^{5}$ Department of Interventional Cardiology and Angiology, National Institute of Cardiology, Warszawa, Poland

${ }^{6}$ Department of Anesthesiology and Intensive Care, University Hospital, Kraków, Poland

'Department of Cardiology, Institute of Medical Sciences, University of Opole, Opole, Poland

${ }^{8} 3^{\text {rd }}$ Department of Cardiology, Faculty of Medical Sciences in Zabrze, Medical University of Silesia, Katowice, Poland

${ }^{9}$ Department of Cardiac Surgery, Medical University of Bialystok, Białystok, Poland

${ }^{10}$ Department of Cardiac Surgery and Transplantology, Poznan University of Medical Sciences, Poznań, Poland

"John Paul II Hospital, Kraków, Poland

${ }^{12}$ Department of Cardiovascular Surgery and Transplantology, Institute of Cardiology, Jagiellonian University Medical College, Kraków, Poland

${ }^{13}$ Department of Invasive Cardiology, Medical University of Bialystok, Białystok, Poland

${ }^{14}$ National Institute of Cardiology, Warszawa, Poland

${ }^{15}$ Department of Medical Rescue, Poznan University of Medical Sciences, Poznań, Poland

${ }^{16}$ Intensive Cardiac Care Unit, $1{ }^{\text {st }}$ Department of Cardiology and Angiology, Silesian Center of Heart Diseases, Zabrze, Poland

${ }^{17}$ Intensive Cardiac Care Unit, University Hospital, Kraków, Poland

${ }^{18}$ Department of Cardiac Surgery, Heart and Lung Transplantation and Mechanical Circulatory Support, Silesian Center For Heart Diseases, Zabrze, Poland

${ }^{19}$ Pomeranian Medical University, Szczecin, Poland

${ }^{20}$ Division of Cardiology and Structural Heart Diseases, Medical University of Silesia, Katowice, Poland

${ }^{21}$ Department of Cardiac Surgery, School of Medicine in Katowice, Medical University of Silesia, Katowice, Poland

*Both authors equally contributed to this work 
Correspondence to: Prof. Agnieszka Tycińska, MD, PhD,

Department of Cardiology, Medical University of Bialystok, M Skłodowskiej-Curie 24A 15-276 Białystok, Poland, phone: +48857486656 , e-mail:

agnieszka.tycinska@gmail.com Copyright by the Author(s), 2021 Kardiol Pol. 2021; 79 (12): 1399-1410; DOI: 10.33963/KP.a2021.0169

Received:

October 24, 2021

Revision accepted:

December 2, 2021

Published online:

December 3, 2021

\section{A B S T R A C T}

Mechanical circulatory support (MCS) methods are used in patients with both acute and chronic heart failure, who have exhausted other options for pharmacological or surgical treatments. The purpose of their use is to support, partially or completely, the failed ventricles and ensure adequate organ perfusion, which allows patients to restore full cardiovascular capacity, prolonging their life and effectively improving its quality. The three most popular devices include an intra-aortic balloon pump (IABP), percutaneous assist devices (including Impella, TandemHeart), and venoarterial extracorporeal membrane oxygenation (VA-ECMO). A multidisciplinary approach with the special participation of the Heart Team is required to determine the proper MCS strategy, the choice of the supporting method, and the time of its use. The studies published so far do not allow us to determine which MCS method is the safest and the most effective. Thus, the site experience and accessibility of the method seem to matter most today. MCS finds particular application in patients with acute coronary syndromes complicated by refractory cardiogenic shock, as well as in patients with acute heart failure of the high potential for reversibility. It can also serve as a backup for percutaneous coronary interventions of high risk (complex and high-risk indicated percutaneous coronary intervention [PCl], complex and high-risk indicated PCI [CHIP]). The use of appropriate supportive drugs, precise hemodynamic and echocardiographic monitoring, as well as optimal non-invasive or mechanical ventilation, are extremely important in the management of a patient with MCS. The most serious complications of MCS include bleeding, thromboembolic events, as well as infections, and hemolysis.

Key words: mechanical circulatory support-type and extension, indications and complications, multidisciplinary approach, hemodynamic and echocardiographic monitoring, ventilation and pharmacotherapy

Kardiol Pol 2021; 79, 12: 1399-1410

\section{INTRODUCTION}

For the past 20 years, there has been an ongoing search for novel medical therapies aimed at reducing mortality in patients with cardiogenic shock (CS) and acute cardiopulmonary failure. However, as the mortality rate in this population continues to be high, reaching $40 \%$ to $50 \%$, the next step is to develop other therapeutic methods, such as mechanical circulatory support (MCS). Unfortunately, the choice of an MCS strategy is currently not supported by a sufficient number of studies providing unequivocal data. Precise recommendations for the use of MCS are also lacking.

The multivariable risk-benefit profiling to select patients for MCS requires a multidisciplinary approach, with the involvement of a Heart Team including a general cardiologist, an invasive cardiologist, an intensivist, a cardiac surgeon, and other specialists if needed. Due to advanced technology, current MCS systems enable full recovery of circulatory function, thus improving longevity and the quality of life of patients. Guidelines developed by American and European societies support the use of MCS to achieve full or partial ventricular support and adequate end-organ perfusion in patients with acute and chronic heart failure (HF), in whom all other medical or surgical treatments have failed. The management strategy depends on disease etiology, comorbidities, social and family history, as well as the experience of the implanting center. The choice of the MCS method, including the duration (short-, mid-, or long-term), type, and the extent of support, depends primarily on the patient's clinical status at the time of decision-making and destination therapy. In some patients, MCS is used as a bridge to transplant or a bridge to candidacy (BTC), while in others - as a bridge to recovery (BTR). Moreover, MCS may serve as a destination therapy for patients with contraindications to orthotopic heart transplantation (OHT) and as a bridge-to-decision (BTD) therapy for patients with acute HF (AHF) complicated by sudden cardiac arrest, who have an uncertain prognosis.

In this expert opinion statement, we discuss current approaches to MCS, as well as the management of intensive cardiac-care patients who require this type of treatment.

\section{INDICATIONS FOR MECHANICAL CIRCULATORY SUPPORT}

\section{Patients with acute coronary syndromes complicated by cardiogenic shock}

The major indication for MCS in patients with acute coronary syndrome is refractory CS complicating acute myocardial infarction (MI). Numerous MCS devices are available, with the 3 most popular being an intra-aortic balloon pump (IABP), a percutaneous ventricular assist device (VAD), such as Impella or TandemHeart, and venoarterial extracorporeal membrane oxygenation (VA-ECMO). They can be applied either alone or in combination and may provide right ventricular, left ventricular (LV), or biventricular support. According to the current European Society of Cardiology (ESC) guidelines, in patients with CS refractory to inotropic/vasopressor drugs, the early use of short-term MCS should be considered as a BTR or as a BTD on long-term VAD, OHT, or therapy withdrawal [1, 2]. IABP 
may be considered in patients with CS, including treatment of the mechanical complication of acute MI or as a BTD on long-term MCS or OHT. However, IABP is not routinely recommended in post-MI CS.

To date, observational and randomized studies on MCS did not reveal any notable benefits in terms of improved survival in patients with CS complicating acute MI. Therefore, while awaiting further evidence, it seems that the most appropriate approach to the selection and use of the MCS device is for each center to develop a detailed protocol for the management of patients with CS complicating acute MI. The optimal timing for the initiation of MCS seems to be "classic" CS (stage C according to the Society for Cardiovascular Angiography and Interventions classification), with lactate levels higher than $2 \mathrm{mmol} / \mathrm{l}$ and before the onset of severe multiple organ injury. The selection between a percutaneous VAD and VA-ECMO should be guided primarily by the experience of the implanting center, both in terms of device implantation skills and patient management at the intensive cardiac care unit, and secondarily, by equipment availability.

\section{Patients with acute heart failure}

According to the recent 2021 European Society of Cardiology (ESC) guidelines, in patients with AHF, short-term MCS may be necessary to increase cardiac output and improve organ perfusion. Short-term MCS can be considered as a BTR or BTD [2]. Recent studies have shown that using a "standardized team-based approach" and predefined algorithms for early MCS implantation, supported by close monitoring (invasive hemodynamics, lactate levels, markers of end-stage organ damage), may potentially improve survival [3].

Mechanical circulatory support should be first considered in patients with AHF or CS with a high potential for recovery (e.g., in the course of myocarditis, peripartum cardiomyopathy, or Takotsubo syndrome) [2]. However, selecting an appropriate device remains a challenge owing to the lack of data from large randomized controlled trials. Although the guidelines do not recommend routine use of an IABP in patients with CS [2], it may still be considered in patients with hemodynamic instability, especially that of non-ischemic etiology and refractory to drug therapy, as a BTD or BTR. Other short-term MCS devices were compared with IABP in small randomized trials with inconclusive results [4]. Impella and TandemHeart were shown to offer greater hemodynamic benefits vs IABP in patients with CS, although without effect on survival [5]. Therefore, IABP remains the most common MCS device. High-quality evidence on the use of Impella in patients with CS without acute MI is lacking.

It was shown that VA-ECMO offers a high degree of biventricular support in a wide range of clinical scenarios. Therefore, it is increasingly used as the first-line strategy in patients requiring MCS $[6,7]$. Aso et al. [8] reported significant benefits of VA-ECMO use in combination with IABP vs VA-ECMO alone in patients with CS, including improved survival and a higher proportion of patients weaned from VA-ECMO. The use of Impella in patients on VA-ECMO support (ECMELLA) was also reported to improve treatment outcomes [9]. The use of MCS (ECMO, Impella RP) may be also considered in isolated acute right $\operatorname{HF}[10,11]$.

\section{SHORT-TERM MECHANICAL CIRCULATORY SUPPORT IN INTERVENTIONAL CARDIOLOGY}

In interventional cardiology, indications for percutaneous left VAD (LVAD) implantation may be both urgent and elective. Urgent indications are directly related to the patient's clinical status and were described above. This refers primarily to patients with CS or acute ischemic HF who require concomitant coronary procedures.

The need for elective LVAD implantation results from the changing profile of patients undergoing percutaneous coronary interventions ( $\mathrm{PCls}$ ). There is currently no universal definition of complex and high-risk indicated $\mathrm{PCI}$ (CHIP). Nevertheless, in recent years, a range of factors associated with higher procedural risk have been identified (Table 1) $[10,12]$. In severe peripheral vascular disease, alternative access, such as a subclavian or axillary artery, may be considered. The use of axial-flow pumps is contraindicated in severe aortic stenosis or moderate/severe aortic regurgitation. Patient eligibility for percutaneous LVAD implantation during CHIP should be determined by a Heart Team. The decision-making should be guided by cardiac output, the presence of comorbidities, the duration of support, the risk of bleeding, as well as ischemic events associated with the planned coronary intervention and the type of MCS device used, including the risk of local complications.

Local complications (bleeding, hematomas, limb ischemia) constitute an important limitation to the use of percutaneous LVAD. Therefore, it is necessary to puncture properly and to secure hemostasis after the procedure. Notably, the risk of complications increases with a longer duration of LV support. Therefore, in the case of elective CHIP procedures, an optimal approach is to remove the device on completion of the procedure. A comparison of available percutaneous ventricular assist devices, their characteristics, and hemodynamic effects is presented in Table 2.

\section{SHORT- AND LONG-TERM MECHANICAL CIRCULATORY SUPPORT}

Orthotopic heart transplantation remains the treatment of choice for patients with end-stage HF, mainly because of very good long-term outcomes. Thanks to advanced technology, the implantation of MCS devices (particularly centrifugal continuous-flow LVADs) was shown to yield similar 5-year outcomes as OHT. Considering a limited number of donors, the differences between the bridge to transplant and destination therapy strategies are becoming increasingly less distinct, and this tendency will be even more pronounced in the future. The use of MCS as a BTT therapy is summarized in Table 3. 
Table 1. Factors associated with complex and high-risk indicated percutaneous coronary intervention (CHIP)

\begin{tabular}{|c|c|}
\hline 1. Clinical characteristics of high-risk patients & 2. Anatomical and morphological characteristics of high-risk lesions \\
\hline $\begin{array}{l}\text { - } \text { advanced age ( }>75 \text { years) } \\
\text { - } \text { diabetes } \\
\text { - } \text { heart failure with } \mathrm{LVEF} \leq 35 \% \\
\text { - } \text { acute coronary syndrome } \\
\text { - } \text { previous cardiac surgery } \\
\text { - } \text { seripheral vascular disease } \\
\text { - } \text { chronic obstructive pulmonary disease } \\
\text { - } \text { concomitant severe aortic valve disease or severe mitral regurgitation }\end{array}$ & $\begin{array}{l}\text { - unprotected left main coronary artery disease } \\
\text { - degenerated vein grafts } \\
\text { - severely calcified lesions requiring rotational atherectomy } \\
\text { - a single remaining patent vessel } \\
\text { - chronic total occlusion, especially in patients with multivessel disease }\end{array}$ \\
\hline
\end{tabular}

Abbreviations: GFR, glomerular filtration rate; LVEF, left ventricular ejection fraction

Table 2. Technical and clinical characteristics of common percutaneous mechanical circulatory support devices

\begin{tabular}{|c|c|c|c|c|c|}
\hline Characteristics & IABP & VA-ECMO & $\begin{array}{c}\text { Impella } \\
(2.5, \mathrm{CP}, 5.0,5.5)\end{array}$ & IVAC 2L & TandemHeart \\
\hline Inflow/outflow & Aorta & Right atrium — aorta & Left ventricle - aorta & $\begin{array}{l}\text { Left ventricle - } \\
\text { aorta }\end{array}$ & Left ventricle - aorta \\
\hline $\begin{array}{l}\text { Mechanism of action } \\
\text { Pneumatic }\end{array}$ & & Centrifugal flow & Axial flow & Pulsatile flow & Centrifugal flow \\
\hline Site and type of access & $\begin{array}{l}\text { Femoral artery/ } \\
\text { /percutaneous }\end{array}$ & $\begin{array}{l}\text { Femoral artery and } \\
\text { vein/percutaneous }\end{array}$ & $\begin{array}{l}\text { Femoral artery/ } \\
\text { /percutaneous }\end{array}$ & $\begin{array}{l}\text { Femoral artery/ } \\
\text { /percutaneous }\end{array}$ & $\begin{array}{l}\text { Femoral artery and vein/ } \\
\text { /percutaneous }\end{array}$ \\
\hline Sheath size (Fr) & $7-8$ & $\begin{array}{l}\text { Venous: } 17-21 \\
\text { Arterial: } 16-19\end{array}$ & $14-21$ & 17 & $\begin{array}{c}\text { Venous: } 21 \\
\text { Arterial: } 12-19\end{array}$ \\
\hline Maximum flow (I/min) & $0.3-0.5$ & 7.0 & $3.7-5.5$ & 2.8 & 4.0 \\
\hline Duration of support & $2-5$ days & $7-10$ days & $6 \mathrm{~h}-10$ days & $6 \mathrm{~h}-10$ days & Up to 14 days \\
\hline LV function-dependent & + & - & - & - & - \\
\hline Synchrony with cardiac function & + & - & - & - & - \\
\hline Left ventricular unloading & + & - & +++ & + & +++ \\
\hline Afterload & $\downarrow$ & $\uparrow \uparrow$ & $\downarrow$ & $\downarrow$ & $\uparrow$ \\
\hline MAP & $\uparrow$ & $\uparrow \uparrow$ & $\uparrow \uparrow$ & $\uparrow \uparrow$ & $\uparrow \uparrow$ \\
\hline Cardiac index & $\uparrow$ & $\uparrow \uparrow \uparrow$ & $\uparrow \uparrow \uparrow$ & $\uparrow \uparrow$ & $\uparrow \uparrow \uparrow$ \\
\hline PCWP & $\downarrow$ & $\leftrightarrow$ & $\downarrow \downarrow$ & $\downarrow$ & $\downarrow \downarrow$ \\
\hline LVEDP & $\downarrow$ & $\leftrightarrow$ & $\downarrow \downarrow$ & $\downarrow \downarrow$ & $\downarrow \downarrow \downarrow$ \\
\hline Coronary artery perfusion & $\uparrow$ & $\leftrightarrow$ & $\uparrow$ & $\uparrow$ & $\leftrightarrow$ \\
\hline Myocardial oxygen consumption & $\downarrow$ & $\leftrightarrow$ & $\downarrow \downarrow$ & $\downarrow \downarrow$ & $\downarrow \leftarrow$ \\
\hline $\begin{array}{l}\text { Difficulties in device implantation } \\
\text { and patient management }\end{array}$ & + & +++ & ++ & ++ & +++ \\
\hline Possible complications & $\begin{array}{l}\text { Lower limb ische- } \\
\text { mia, bleeding }\end{array}$ & $\begin{array}{l}\text { Lower limb ischemia, } \\
\text { bleeding, hemolysis }\end{array}$ & $\begin{array}{c}\text { Hemolysis, lower limb } \\
\text { ischemia, } \\
\text { bleeding }\end{array}$ & $\begin{array}{l}\text { Hemolysis, lower } \\
\text { limb ischemia, } \\
\text { bleeding }\end{array}$ & $\begin{array}{c}\text { Hemolysis, lower limb } \\
\text { ischemia, } \\
\text { bleeding }\end{array}$ \\
\hline Contraindications & $\begin{array}{c}\text { Moderate to } \\
\text { severe aortic re- } \\
\text { gurgitation, critical } \\
\text { femoral/iliac artery } \\
\text { stenosis }\end{array}$ & $\begin{array}{l}\text { Moderate to severe } \\
\text { aortic regurgitation, } \\
\text { severe iliac/femoral } \\
\text { artery stenosis, } \\
\text { contraindications to } \\
\text { anticoagulation }\end{array}$ & $\begin{array}{l}\text { Severe aortic valve dise- } \\
\text { ase, mechanical aortic } \\
\text { valve, left ventricular } \\
\text { thrombus, } \\
\text { severe iliac/femoral artery } \\
\text { stenosis, } \\
\text { contraindications to } \\
\text { anticoagulation }\end{array}$ & $\begin{array}{c}\text { Severe aortic } \\
\text { valve disease, } \\
\text { mechanical } \\
\text { aortic valve, } \\
\text { left ventricular } \\
\text { thrombus, } \\
\text { severe iliac/ } \\
\text { femoral artery } \\
\text { stenosis, } \\
\text { contraindica- } \\
\text { tions to anti- } \\
\text { coagulation }\end{array}$ & $\begin{array}{l}\text { Moderate to severe aortic } \\
\text { regurgitation, } \\
\text { left atrial thrombus, } \\
\text { severe iliac/femoral artery } \\
\text { stenosis, contraindica- } \\
\text { tions to anticoagulation }\end{array}$ \\
\hline
\end{tabular}

Abbreviations: IABP, intra-aortic balloon pump; VA-ECMO, venoarterial extracorporeal membrane oxygenation; LV, left ventricular; MAP, mean arterial pressure; PCWP, pulmonary capillary wedge pressure; LVEDP, left ventricular end-diastolic pressure 
Table 3. Mechanical circulatory support as a bridge to transplant

\begin{tabular}{|c|c|}
\hline \multicolumn{2}{|r|}{ MCS as a bridge to transplant } \\
\hline Indications for implantation & When? \\
\hline $\begin{array}{l}\text { 1. In patients referred for OHT, with an esti- } \\
\text { mated prolonged waiting time for donor's } \\
\text { heart (e.g., body mass }>100 \mathrm{~kg} \text {; blood group } \\
\text { B), with frequent decompensation episodes } \\
\text { (INTERMACS 4) or hospitalizations requiring } \\
\text { inotropic treatment (INTERMACS 3) }\end{array}$ & $\begin{array}{l}\text { 1. In patients referred for urgent OHT, MCS implantation should be conside- } \\
\text { red after a waiting time span defined by the Heart Failure Heart Team and } \\
\text { dependent on the patient's hemodynamic status, disease etiology, and } \\
\text { technical feasibility of implantation. If the patient is hemodynamically sta- } \\
\text { ble and receives inotropic support or short- to mid-term MCS, the waiting } \\
\text { time should not exceed } 2 \text { weeks }\end{array}$ \\
\hline $\begin{array}{l}\text { 2. In patients with dilated or ischemic cardio- } \\
\text { myopathy with left ventricular impairment } \\
\text { (or distention) and normal or slightly impa- }\end{array}$ & $\begin{array}{l}\text { 2. In patients referred for urgent OHT, with severe arrhythmia or increased } \\
\text { catecholamine levels, an MCS device should be implanted within } 48 \text { to } \\
72 \text { hours }\end{array}$ \\
\hline $\begin{array}{l}\text { ired right ventricular systolic function } \\
\text { 3. In patients without contraindications to } \\
\text { long-term anticoagulant treatment with }\end{array}$ & $\begin{array}{l}\text { 3. In patients referred for elective OHT, long-term MCS (preferably CF-LVAD) } \\
\text { may be considered in candidates with low chances of receiving an organ } \\
\text { (body mass }>120 \mathrm{~kg} \text { ) }\end{array}$ \\
\hline $\begin{array}{l}\text { vitamin } \mathrm{K} \text { antagonist and antiplatelet } \\
\text { therapy with acetylsalicylic acid, with adequ- } \\
\text { ate support from the family or relatives, } \\
\text { independent or only slightly limited in daily }\end{array}$ & $\begin{array}{l}\text { 4. In patients classified as INTERMACS class } 1 \text { (cardiogenic shock), implan- } \\
\text { tation of mid-term MCS devices is preferred, with a subsequent switch to } \\
\text { long-term support (LVAD or TAH) in the absence of an organ donor within } \\
\text { the time span defined by the team (usually within 10-30 days) }\end{array}$ \\
\hline
\end{tabular}

Estimated duration of mechanical support

In this population, long-term LVAD support is preferred. This type of treatment is associated with 2- to 5-year survival, which is comparable to that for $\mathrm{OHT}$

\section{Indications for implantation}

If the condition that constitutes a contraindication to transplant is potentially reversible or curable. MCS therapy may increase the chances of curing a concomitant condition (eg, pulmonary hypertension, early-stage cancer, or a post-cancer treatment condition within a period of fewe than 5 years from intervention/treatment)

\section{MCS as a bridge to transplant}

\section{When?}

In hemodynamically stable patients classified as INTERMACS class 3-5. Usually as an elective procedure. The intervention should be preceded by specialist consultations, and subsequent treatment should be administered in cooperation with an implantation or transplantation center

\section{Indications for implantation}

In cardiogenic shock (INTERMACS 1) or in the case of hemodynamic deterioration and/or multiple organ injury despite therapy escalation (INTERMACS 2)

\section{MCS as a bridge to decision}

When?

Simultaneously with the decision to institute mechanical circulatory support, often during resuscitation

\section{Estimated duration of mechanical support}

Unknown, potentially long
What type of device should be used?

ong-term CF-LVAD is preferred. If biventricular support is needed TAH or biventricular VAD may be used

\section{Estimated duration $\quad$ What type of device should of mechanical support}

Unknown, potential- Owing to the availability and quick ly moderately long implantation procedure, short-term MCS devices are preferred (mainly VA-ECMO). In potentially reversible cardiogenic shock, mid-term devices can be are preferred (eg, LEVITRONIX)

\section{Indications for implantation}

In acute heart failure without permanent damage to the contractile apparatus and if recovery of normal function is possible (eg, myocarditis, poisoning, peripartum cardiomyopathy, postcardiotomy or post-OHT cardiogenic shock, rarely in dilated cardiomyopathy)
MCS as a bridge to recovery

When?

The decision should be made immediately after pharmacological options have failed long (months) or, less frequently, long (years)

\section{Estimated duration of mechanical support}

\section{Unknown, poten-} ally moderately

\section{What type of device should} be used?

Owing to the availability and quick implantation procedure, midterm MCS devices are preferred - centrifugal-flow pumps such as LEVITRONIX or pneumatic pumps such as Religa or Berlin Heart (in pediatric patients). The use of CF-LVAD is contraindicated or implantation is technically not feasible because the pathology often involves both ventricles (poisoning, myocarditis)

\begin{tabular}{|c|c|c|c|}
\hline \multicolumn{4}{|c|}{ MCS as destination therapy } \\
\hline Indications for implantation & When? & $\begin{array}{c}\text { Estimated duration } \\
\text { of mechanical } \\
\text { support }\end{array}$ & $\begin{array}{l}\text { What type of device should } \\
\text { be used? }\end{array}$ \\
\hline $\begin{array}{l}\text { Not eligible for OHT, most often due to age } \\
\text { (>70 years) or with chronic comorbidities: } \\
\text { chronic kidney disease, irreversible pulmonary } \\
\text { hypertension, or with contraindications to im- } \\
\text { munosuppressive treatment (history of cancer) } \\
\text { or pathological obesity }\end{array}$ & $\begin{array}{l}\text { Preferred - if the patient presents with signs } \\
\text { and symptoms of heart failure with at least } \\
2 \text { hospitalizations per year (INTERMACS } \\
4-5 \text { ) The procedure should be performed } \\
\text { in hemodynamically stable patients and } \\
\text { should be preceded by gastrointestinal } \\
\text { imaging studies (gastroscopy, colonoscopy) } \\
\text { to exclude contraindications to chronic } \\
\text { anticoagulation }\end{array}$ & Long-term & $\begin{array}{l}\text { CF-LVAD preferred. TAH is not ap- } \\
\text { proved for use in this indication }\end{array}$ \\
\hline
\end{tabular}

MSC, mechanical circulatory support; OHT, orthotopic heart transplantation; CF-LVAD, continuous-flow left ventricular assist device; TAH, total artificial heart; VA-ECMO, veno-arterial extracorporeal membrane oxygenation; VAD, ventricular assist device, LVAD, left ventricular assist device 


\section{EXTRACORPOREAL MEMBRANE OXYGENATION SUPPORT FROM THE PERSPECTIVE OF AN INTERVENTIONAL CARDIOLOGIST, AN INTENSIVIST, AND A CARDIAC SURGEON}

\section{Interventional cardiology}

There is a general agreement that access to an effective MCS device is needed in at least 2 clinical scenarios in the setting of interventional cardiology: during a $\mathrm{PCl}$ in patients with $\mathrm{MI}$ complicated by CS and in patients undergoing CHIP. Since the publication of the IABP-SHOCK II study, which revealed significant limitations to IABP use, there has been an increasing interest in other MCS strategies, including VA-ECMO $[13,14]$.

Originally used in cardiac surgery, VA-ECMO has become an indispensable part of modern intensive care. In Poland, the vast majority of MCS equipment can be found at cardiac surgery and intensive care units, outside the catheterization laboratories. It is widely acknowledged that time is a key factor in interventional treatment for ST-segment elevation myocardial infarction and CS. Relocating and launching VA-ECMO in the catheterization laboratory necessitate an immediate decision and highly effective team cooperation based on simple and clear management algorithms. Unfortunately, the lack of such guidelines hinders the application of VA-ECMO. Moreover, the prolonged VA-ECMO use in patients with CS increases afterload, and, in some patients, the lack of LV decompression causes progressive distention with profound LV failure. In such cases, additional or supportive active-unloading therapy with a percutaneous axial-flow pump (ie, Impella) is mandatory. This might improve survival and reduce the long-term risk of HF caused by LV overload. However, such a combined MCS strategy for CS entails additional risk, with vascular complications in the first place. Retroperitoneal hemorrhage, arterial laceration from the use of large-bore femoral cannulas, and distal limb ischemia underlie the subsequent higher need for transfusion and the risk of acute kidney injury. Thus, meticulous use of the procedure with the help of a vascular surgeon and/or safety devices is highly recommended. All things considered, it must be emphasized that the complexity and cost-effectiveness of the combined approach are high and the number of studies reporting such benefits is limited $[9,15]$.

The decision on whether to use hemodynamic support in patients undergoing CHIP remains a challenge, with the widely available risk scores (EuroSCORE II, Syntax I, and II) being of limited supportive value for decision-making. On the one hand, the individual patient's characteristics should be assessed, including comorbidities, LV function, previous revascularization procedures, as well as the estimated duration and complexity of $\mathrm{PCl}$. On the other hand, the feasibility of the procedure in extremely difficult cases (rotational atherectomy, treatment of chronic total occlusion, or distal left main artery stenosis) has to be ac- curately assessed. It is important to mention the problem of limb ischemia and the possibility of its prevention (both Impella and ECMO) by puncturing the antegrade artery below the site of large vascular access and connecting the sheath with the second arterial access, which ensures the inflow of blood to the limb. It is also important to secure the removal of the device by a vascular surgeon or using a hemostatic system.

The most important aspects to consider in MCS strategy selection depending on a clinical scenario are presented in Table 4.

\section{Intensive care}

The typical indications for VA-ECMO in the intensive care setting include refractory CS, massive pulmonary embolism, an overdose of cardiotoxic drugs, or severe hypothermia [16]. The use of VA-ECMO during cardiopulmonary resuscitation in hospitalized patients was reported to increase survival from $20 \%$ to $40 \%$ [17]. While the institution of ECMO itself does not cure a patient with organ failure, it provides more time to implement therapies aimed at reversing the underlying pathological process.

The key to effective VA-ECMO therapy is a high standard of intensive care achieved and maintained by continuous medical education together with the assessment of therapy outcomes and failures [18]. The intensivist working at an ECMO unit is responsible for blood flow optimization in the ECMO system and a daily echocardiographic assessment of LV emptying. The success of VA-ECMO therapy is also determined by such factors as the availability of a protocol for LV unloading using different strategies, expertise in invasive mechanical ventilation, and the ability to identify and reverse differential hypoxia [19]. The most common modes of LV unloading during VA-ECMO are IABP, percutaneous transaortic LVAD (Impella), atrial septostomy, and direct surgical LV venting. Finally, an important determinant of VA-ECMO success is knowledge of escalation strategies (LVAD, OHT), as well as conscious decision-making skills in terms of therapy de-escalation.

\section{Cardiac surgery}

In cardiac surgery, VA-ECMO devices are indicated for circulatory support in patients with postcardiotomy low cardiac output syndrome and refractory CS [20] (stage D ["deteriorating"] and E ["extremis"] according to the Society for Cardiovascular Angiography and Interventions Clinical Expert Consensus Statement on the Classification of Cardiogenic Shock). VA-ECMO is used directly during the procedure in patients with severe hemodynamic collapse, in patients who cannot be weaned from cardiopulmonary bypass after the procedure, or in those who develop low cardiac output syndrome immediately after the procedure. Moreover, VA-ECMO is typically used as a BTR strategy. In some cases, it may be used as a BTD that includes either LVAD implantation or OHT. The most common complication of postcardiotomy ECMO circulatory support is major 
Table 4. Use of percutaneous ventricular assist devices in complex and high-risk indicated percutaneous coronary intervention (CHIP)

\begin{tabular}{|c|c|c|c|}
\hline Device & IABP & AFP & VA-ECMO \\
\hline \multicolumn{4}{|c|}{ Use of percutaneous VAD in CHIP } \\
\hline Indications & $\begin{array}{l}\text { In selected cases when the vascular } \\
\text { access precludes AFP use (common } \\
\text { femoral artery diameter }>4 \mathrm{~mm} \text {, } \\
\text { without excessive tortuosity) }\end{array}$ & $\begin{array}{l}\text { Indicated in cases with adequate } \\
\text { vascular access (common femoral } \\
\text { artery diameter }>6 \mathrm{~mm} \text {, without } \\
\text { excessive tortuosity) }\end{array}$ & $\begin{array}{c}\text { To be considered if biventricular support } \\
\text { is required, with the need for oxygena- } \\
\text { tion support }\end{array}$ \\
\hline $\begin{array}{l}\text { Evidence from clinical trials and } \\
\text { studies }\end{array}$ & BCIS-1 study & PROTECT II and cohort studies & No data available \\
\hline \multicolumn{4}{|c|}{ Use of percutaneous VAD in patients with HR-AMI without CS } \\
\hline Indications & Not recommended & $\begin{array}{l}\text { Impella CP implantation is possible } \\
\text { and effective as the primary strate- } \\
\text { gy for left ventricular unloading }\end{array}$ & Not recommended \\
\hline $\begin{array}{l}\text { Evidence from clinical trials and } \\
\text { studies }\end{array}$ & IABP-SHOCK II & $\begin{array}{l}\text { Preclinical studies; a single pilot } \\
\text { study }\end{array}$ & No data available \\
\hline \multicolumn{4}{|c|}{ Use of percutaneous VAD in patients with CS } \\
\hline Indications & $\begin{array}{l}\text { Routine use is not recommended; } \\
\text { it may be considered in patients } \\
\text { with mechanical complications of } \\
\text { AMI and patients with CS unrelated } \\
\text { to AMI. }\end{array}$ & $\begin{array}{l}\text { Impella CP may be used for short- } \\
\text { term support in patients with CS } \\
\text { (stage C or D) with a potentially } \\
\text { reversible cause or in candidates } \\
\text { for VAD implantation or heart } \\
\text { transplant }\end{array}$ & $\begin{array}{l}\text { May be used as short-term support in } \\
\text { patients with CS (stage } C, D \text {, or } E \text { ), parti- } \\
\text { cularly in those with respiratory failure, } \\
\text { with a potentially reversible cause, or in } \\
\text { candidates for VAD implantation or heart } \\
\text { transplant. } \\
\text { To be considered in patients with refrac- } \\
\text { tory sudden cardiac arrest }\end{array}$ \\
\hline $\begin{array}{l}\text { Evidence from clinical trials and } \\
\text { studies }\end{array}$ & IABP-SHOCK II & $\begin{array}{l}\text { Small randomized trials and cohort } \\
\text { studies }\end{array}$ & $\begin{array}{l}\text { Prospective and retrospective cohort } \\
\text { studies }\end{array}$ \\
\hline
\end{tabular}

IABP, intra-aortic balloon pump; AFP, axial-flow pumps; VA-ECMO, veno-arterial extracorporeal membrane oxygenation; VAD, ventricular assist device; HR-AMI, heart rupture after acute myocardial infarction; CS, cardiogenic shock; AMI, acute myocardial infarction

bleeding, with almost half of the patients requiring surgical intervention. Postcardiotomy ECMO support is associated with low survival rates (in-hospital mortality, 70\%; 5-year survival, $15 \%$ ).

Moreover, ECMO may be used as short-term MCS in patients classified as INTERMACS level 1 and 2 , in the absence of contraindications and if long-term hemodynamic support or OHT is feasible [16]. Preoperatively, ECMO is used to achieve stability in patients with CS. By restoring the pump output, ECMO stabilizes organ function (mainly the kidneys and the liver), resolves potential bleeding disorders, and allows a comprehensive assessment of the patient's condition before deciding on subsequent management.

VA-ECMO can lead to the development of Harlequin syndrome, which is associated with a difference in oxygenation in the blood reaching the upper and lower half of the body. The upper body receives poorly oxygenated blood pumped by the heart, and the lower body receives well-oxygenated blood from ECMO. This depends on the ratio of cardiac output and influx from ECMO. The solution is to shift the returning cannula closer to the heart (e.g., into the right subclavian artery), central cannulation (through thoracotomy), or add another cannula to the venous system (the so-called veno-arterial-venous ECMO).

\section{HEMODYNAMIC MONITORING OF PATIENTS ON MECHANICAL CIRCULATORY SUPPORT}

Cardiac monitoring in critically ill cardiac patients (particularly those with CS complicating AHF) is fundamental not only for the diagnostic process but also for treatment optimization and outcome evaluation. However, stud- ies conducted so far revealed no significant differences between invasive and minimally invasive or noninvasive hemodynamic monitoring in terms of improved outcomes [21, 22]. It seems that the decision on the type of hemodynamic monitoring in critically ill patients should be guided primarily by a detailed clinical assessment, as well as local equipment availability and training. Advanced monitoring incorporates both noninvasive and invasive continuous hemodynamic monitoring. Noninvasive techniques include clinical assessment: blood pressure, heart rate, diuresis, metabolic parameters, transthoracic and transesophageal echocardiography, impedance cardiography, and noninvasive arterial blood pressure waveform monitoring. Invasive monitoring from arterial and central venous catheters, as well as pulmonary artery catheters, provides the measurement of arterial pressure, intracardiac filling pressures, arterial and venous blood gases, and cardiac index (invasive arterial and venous blood pressure monitoring, venous pressure monitoring, right heart catheterization [thermodilution, continuous cardiac output, mixed venous oximetry], transpulmonary thermodilution [PICCO, LIDCO], Fick method). Additionally, in some cases, it is necessary to assess intra-abdominal pressure to evaluate organ perfusion pressures [23-26]. Notably, no single method of hemodynamic monitoring itself will improve the patient's prognosis: it must implicate proper therapeutic decisions. There are no optimal hemodynamic parameters that would apply to all patients and individual hemodynamic parameters should be combined and integrated depending on the patient's clinical status. Hemodynamic abnormalities depending on the type of MCS device are 
Table 5. Hemodynamic abnormalities depending on the type of mechanical circulatory support device [27]

\begin{tabular}{|c|c|c|c|c|}
\hline & IABP & Impella & TandemHeart & VA-ECMO \\
\hline LV contractility & $\leftrightarrow$ & $\leftrightarrow$ & $\leftrightarrow$ & $\leftrightarrow$ \\
\hline TPR & $\leftrightarrow$ & $\leftrightarrow$ & $\leftrightarrow$ & $\leftrightarrow$ \\
\hline LV flow & $\uparrow$ & $\downarrow$ & $\downarrow$ & $\downarrow$ \\
\hline Total CO & $\uparrow$ & $\uparrow \uparrow$ & $\uparrow \uparrow$ & $\uparrow \uparrow \uparrow$ \\
\hline CVP & $\leftrightarrow$ or $\downarrow$ & $\leftrightarrow$ or $\downarrow$ & $\leftrightarrow$ or $\downarrow$ & $\downarrow$ \\
\hline PCWP & $\leftrightarrow$ or $\downarrow$ & $\downarrow$ & $\downarrow$ & $\uparrow$ or $\leftrightarrow^{\mathrm{a}}$ \\
\hline MAP & $\uparrow$ & $\uparrow \uparrow$ & $\uparrow \uparrow$ & $\uparrow \uparrow$ \\
\hline Total CPO & $\uparrow$ & $\uparrow \uparrow$ & $\uparrow \uparrow$ & $\uparrow \uparrow$ \\
\hline PVA & $\leftrightarrow$ or $\downarrow$ & $\downarrow \downarrow$ & $\leftrightarrow$ or $\downarrow$ & $\uparrow \uparrow$ \\
\hline $\mathrm{MVO}_{2}$ & $\downarrow$ & $\downarrow \downarrow$ & $\leftrightarrow$ or $\downarrow$ & $\uparrow \uparrow$ \\
\hline
\end{tabular}

${ }^{\mathrm{a} E C M O}$ use may lead to a decrease in LV preload, but also may provoke an increase of LV afterload with a subsequent undesirable increase in cardiac work and oxygen consumption

Abbreviations: $\mathrm{CO}$, cardiac output; $\mathrm{CPO}$, cardiac power output; CVP, central venous pressure; $\mathrm{MVO}_{2}$ myocardial oxygen consumption; PVA, pressure-volume area; TPR, total peripheral resistance; other — see Table 2

Table 6. General characteristic and hemodynamic assessment depending on the monitoring method

\begin{tabular}{|c|c|c|c|c|c|c|c|c|c|c|}
\hline Method & $\mathrm{CO} / \mathrm{Cl}$ & CVP/RAP & PAP & LAP & SVR & PVR & TFC & $\mathrm{SvO}_{2} / \mathrm{SCvO}_{2}$ & $\begin{array}{l}\text { Invasive- } \\
\text { ness }\end{array}$ & $\begin{array}{l}\text { Availabi- } \\
\text { lity }\end{array}$ \\
\hline $\begin{array}{l}\text { Pulmonary artery cathe- } \\
\text { terization }\end{array}$ & +++ & +++ & +++ & ++ & +++ & +++ & - & +++ & +++ & +++ \\
\hline Impedance cardiography & $+/++$ & - & - & - & ++ & - & ++ & - & 0 & + \\
\hline $\begin{array}{l}\text { Doppler echocardio- } \\
\text { graphy }\end{array}$ & ++ & ++ & ++ & + & - & - & - & - & $0 /+$ & +++ \\
\hline $\begin{array}{l}\text { Transpulmonary thermo- } \\
\text { dilution }\end{array}$ & +++ & $+/-$ & - & - & - & - & + & + & ++ & +++ \\
\hline $\begin{array}{l}\text { Invasive/ } \\
\text { noninvasive pressure } \\
\text { waveform analysis }\end{array}$ & $+/++$ & - & - & - & - & - & - & - & $++/ 0$ & ++ \\
\hline
\end{tabular}

Abbreviations: $\mathrm{Cl}$, cardiac index; CVP, central venous pressure; LAP, left atrial pressure; PAP, pulmonary artery pressure; PVR, pulmonary vascular resistance; SVR, systemic vascular resistance; $\mathrm{SvO}_{2}$, mixed venous oxygen saturation; $\mathrm{SCvO}_{2}$, central venous oxygen saturation; $\mathrm{RAP}$, right atrial pressure; TFC, total fluid capacity; other — see Figure 1

Table 7. Guideline recommendations for the use of invasive hemodynamic monitoring (see the text)

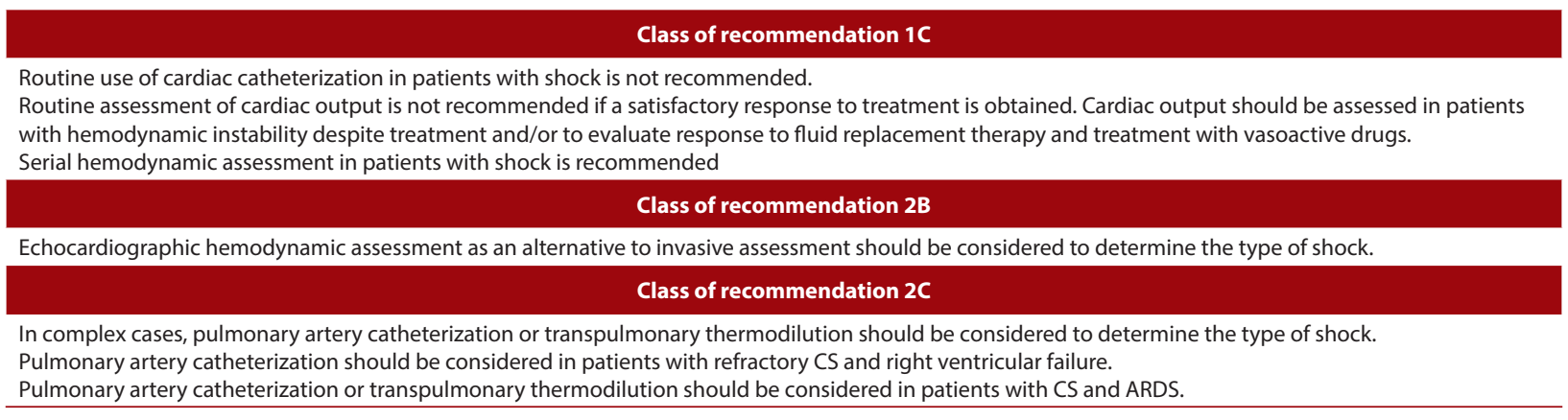

Abbreviations: ARDS, acute respiratory distress syndrome; CS, cardiogenic shock

presented in Table 5 [27], while the hemodynamic parameters assessed using different hemodynamic monitoring methods are presented in Table 6.

In line with the recommendations of the European Intensive Care Society (Consensus on circulatory shock and hemodynamic monitoring Task Force of the European Society of Intensive Care Medicine) [28], cardiac hemodynamic parameters in patients with shock are assessed to identify the type of shock if the clinical presentation is unclear, decide on the type of therapy, and assess treatment response. It seems that in the absence of unequivocal data on the choice of optimal hemodynamic monitoring and predicting survival benefits, these goals are clinically justified. Guideline recommendations for the use of invasive hemodynamic monitoring are summarized in Table 7.

\section{SUPPORTIVE MEDICAL THERAPY IN PATIENTS ON MECHANICAL CIRCULATORY SUPPORT}

Intensive care patients receiving MCS therapy require adequate pharmacological support. Fluid therapy, inotropic/vasopressor therapy, as well as prevention of bleeding and thromboembolic events, are the mainstay of medical therapy in this setting. The myocardial and vascular effects 
Table 8. Effect of inotropic drugs on selected hemodynamic parameters [29]

\begin{tabular}{|c|c|}
\hline Medication/dose & Hemodynamics \\
\hline $\begin{array}{l}\text { Dopamine } \\
0.5-2 \mu \mathrm{g} \cdot \mathrm{kg}^{-1} \cdot \mathrm{min}^{-1}\end{array}$ & $\uparrow \mathrm{CO}$ \\
\hline $\begin{array}{l}\text { Dopamine } \\
5-10 \mu \mathrm{g} \cdot \mathrm{kg}^{-1} \cdot \mathrm{min}^{-1}\end{array}$ & $\uparrow \uparrow C O, \uparrow S V R$ \\
\hline $\begin{array}{l}\text { Dopamine } \\
10-20 \mu \mathrm{g} \cdot \mathrm{kg}^{-1} \cdot \mathrm{min}^{-1}\end{array}$ & $\uparrow \uparrow S V R, \uparrow C O$ \\
\hline $\begin{array}{l}\text { Norepinephrine } \\
0.05-0.4 \mu \mathrm{g} \cdot \mathrm{kg}^{-1} \cdot \mathrm{min}^{-1}\end{array}$ & $\uparrow \uparrow S V R, \uparrow C O$ \\
\hline $\begin{array}{l}\text { Epinephrine } \\
0.01-0.5 \mu \mathrm{g} \cdot \mathrm{kg}^{-1} \cdot \mathrm{min}^{-1}\end{array}$ & $\uparrow \uparrow C O, \uparrow \uparrow S V R$ \\
\hline $\begin{array}{l}\text { Vasopressin } \\
0.02-0.04 \mathrm{U} / \mathrm{min}\end{array}$ & $\uparrow \uparrow S V R, \leftrightarrow P V R$ \\
\hline $\begin{array}{l}\text { Dobutamine } \\
2.5-20 \mu \mathrm{g} \cdot \mathrm{kg}^{-1} \cdot \mathrm{min}^{-1}\end{array}$ & $\uparrow \uparrow C O, \downarrow S V R, \downarrow P V R$ \\
\hline $\begin{array}{l}\text { Milrinone } \\
0.125-0.75 \mu \mathrm{g} \cdot \mathrm{kg}^{-1} \cdot \mathrm{min}^{-1}\end{array}$ & $\uparrow C O, \downarrow S V R, \downarrow P V R$ \\
\hline $\begin{array}{l}\text { Enoximone } \\
2-10 \mu \mathrm{g} \cdot \mathrm{kg}^{-1} \cdot \mathrm{min}^{-1}\end{array}$ & $\uparrow C O, \downarrow S V R, \downarrow P V R$ \\
\hline $\begin{array}{l}\text { Levosimendan } \\
0.05-0.2 \mu \mathrm{g} \cdot \mathrm{kg}^{-1} \cdot \mathrm{min}^{-1}\end{array}$ & $\uparrow C O, \downarrow S V R, \downarrow P V R$ \\
\hline
\end{tabular}

Abbreviations: see Figure 1 and Table 6

of vasoactive medications are summarized in Table 8 [29]. The most common drugs in daily clinical practice, such as dopamine, dobutamine, norepinephrine, or epinephrine, have a relatively low class of recommendation based on experts' opinions. Inotropes should be reserved for patients with poor vital organ perfusion. Their use differs and depends on the therapeutic goal. The ESC guidelines on AHF recommend dobutamine to increase cardiac output in patients with CS (class of recommendation Ilb, level of evidence C) [2]. Norepinephrine is preferred over dopamine to maintain systolic blood pressure in the presence of persistent hypoperfusion (class of recommendation Ilb, level of evidence B) [2]. Vasopressin and its analogs were shown to exert less effect on pulmonary vasoconstriction; therefore, they may be more beneficial in patients with CS and acute right $\mathrm{HF}[30]$.

In recent years, there has been a growing interest in landiolol, an ultra-short-acting $\beta 1$-adrenergic blocker for intravenous use, with a much higher cardioselectivity $(\beta 1 / \beta 2=225)$ than esmolol. So far, the beneficial effect of landiolol on heart rate has been confirmed in patients with advanced HF and supraventricular tachycardia [31].

\section{ECHOCARDIOGRAPHIC MONITORING OF PATIENTS ON MECHANICAL CIRCULATORY SUPPORT}

Transthoracic echocardiography (TTE) and transesophageal echocardiography are widely available, reproducible, and noninvasive tools that can be used at the bedside. Therefore, they have become a standard modality to determine indications for and contraindications to the use of MCS as well as to monitor treatment outcomes. In most cases, TTE is also sufficient for monitoring and assessing the implantation of Impella 2.5 and CP devices. The correct device positioning should be confirmed by echocardiography during the procedure and then at periodic follow-up visits [10]. The monitoring of left and right ventricular function is also recommended. Moreover, TTE is also usually sufficient for monitoring patients on VA-ECMO support. In patients with long-term VAD support, echocardiographic monitoring helps identify early and long-term complications, optimize device settings, and assess improvement in myocardial function. Contraindications to MCS use that can be determined by echocardiography are presented in Table 9.

\section{MECHANICAL VENTILATION IN PATIENTS WITH CARDIOGENIC SHOCK}

Mechanical ventilation in patients with acute decompensated HF is required in the case of acute hypoxemic respiratory failure, excessive breathing effort, electrical instability, or the need for percutaneous or surgical intervention [5]. However, in patients with myocardial infarction, mechanical ventilation is associated with increased mortality (up to $50 \%$ ) [32, 33].

Although a significant proportion of patients with CS complicating MI require respiratory support, there is limited evidence to indicate the ideal modality for mechanical ventilation in this population. This particularly refers to positive pressure ventilation because the inability to operate the device may lead to deterioration of the patient's clinical status. Noninvasive ventilation is widely used in conscious patients with acute systolic HF and acute respiratory failure, leading to improvement of hemodynamic, respiratory, and gas exchange parameters. Although invasive mechanical ventilation is typically used in patients with CS, noninvasive ventilation is a safe and increasingly common option for ventilatory support in conscious patients [34].

Table 9. Contraindications to mechanical circulatory support that can be assessed by echocardiography

\begin{tabular}{|c|c|c|c|}
\hline IABP & Impella & VA-ECMO & LVAD \\
\hline $\begin{array}{l}\text { Aortic regurgitation } \\
\text { Aortic dissection } \\
\text { Peripheral atherosclerosis }\end{array}$ & $\begin{array}{c}\text { LV thrombus } \\
\text { Aortic dissection } \\
\text { LV free wall rupture } \\
\text { Mechanical aortic valve } \\
\text { ASD, VSD }\end{array}$ & $\begin{array}{c}\text { Aortic regurgitation } \\
\text { Aortic dissection } \\
\text { Thrombosis of abdominal aortic } \\
\text { aneurysms }\end{array}$ & $\begin{array}{c}\text { Unrepairable VSD } \\
\text { Active infective endocarditis } \\
\text { Ascending aortic aneurysm } \\
\text { LV free wall rupture } \\
\text { Acute right heart failure }\end{array}$ \\
\hline
\end{tabular}

Abbreviations: ASD, atrial septal defect; VSD, ventricular septal defect; other - see Figure 1, Tables 2 and 3 


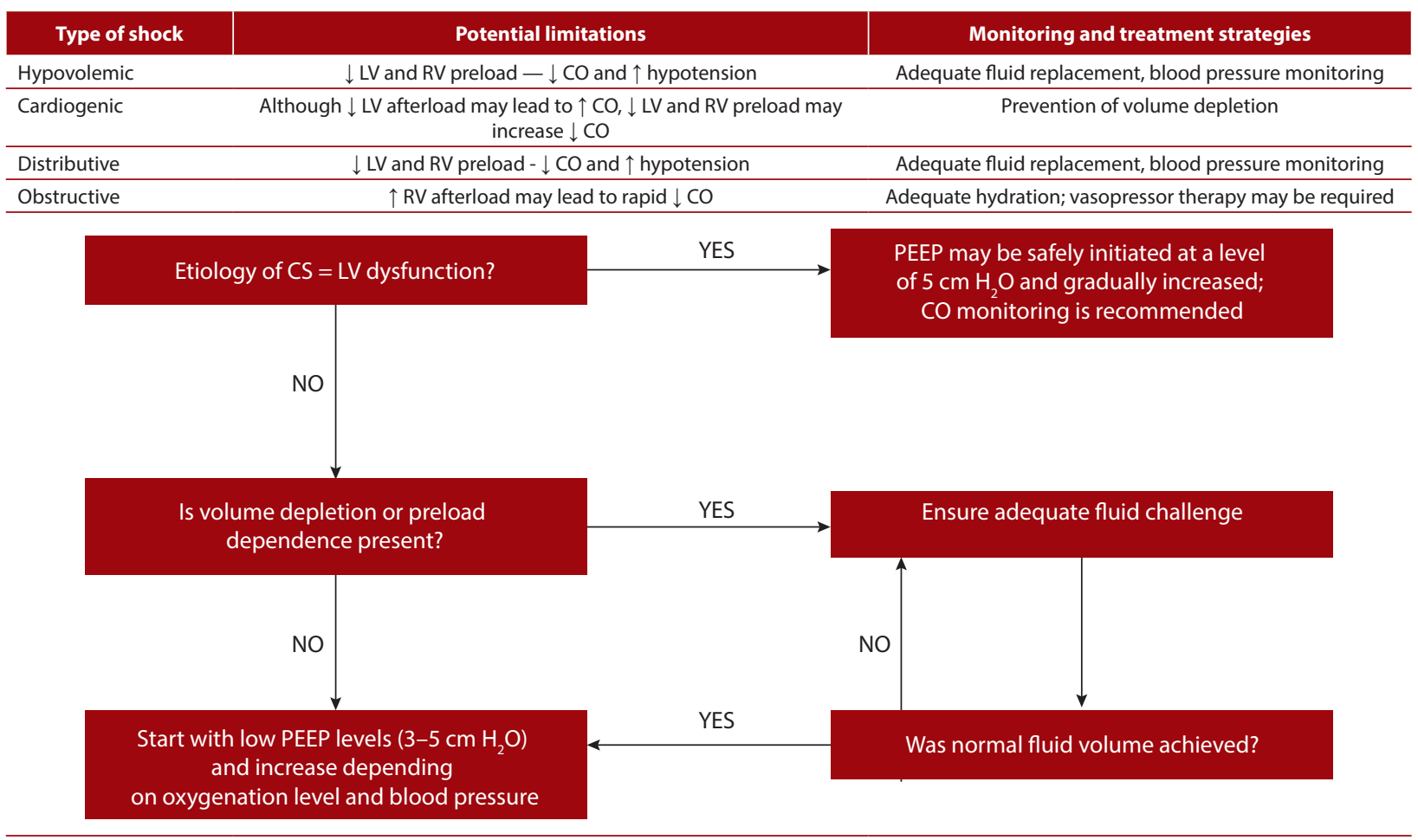

Figure 1. A summary of PEEP ventilation according to the etiology of shock, along with an algorithm for PEEP use in patients with CS Abbreviations: CO, cardiac output; CS, cardiogenic shock; LV, left ventricle; PEEP, positive end expiratory pressure; RV, right ventricle

Table 10. Complications of mechanical circulatory support

\begin{tabular}{|c|c|c|c|}
\hline Complication & IABP $[13,42,43]$ & Impella [43-45] & VA-ECMO [46-50] \\
\hline Bleeding & $\begin{array}{c}3.0 \%-3.3 \% \\
\text { (major bleeding) }\end{array}$ & $\begin{array}{c}\text { 8.5\% (major bleeding); } \\
17.5 \% \text { (bleeding at vascular access) }\end{array}$ & $15 \%$ (major bleeding) \\
\hline $\begin{array}{l}\text { Vascular access-induced ischemia, } \\
\text { vascular complications }\end{array}$ & $3.8 \%-7.5 \%$ & $\begin{array}{c}<4 \% \text { (vascular access-induced ischemia) } \\
9.8 \% \text { (vascular complications) }\end{array}$ & $10 \%-70 \%$ \\
\hline Stroke & $0.7 \%$ & $<2 \%$ & $17 \%$ \\
\hline Sepsis/infection & $15.7 \%$ & $35.3 \%$ & $9 \%$ \\
\hline Other & & tamponade, $1.7 \%$; hemolysis, $5 \%-10 \%$ & $\begin{array}{c}\text { kidney dysfunction, } 22 \% \text {; } \\
\text { mesenteric ischemia, } 9 \% \text {; hemolysis, } 4 \%\end{array}$ \\
\hline
\end{tabular}

Abbreviations: see Table 2

High-flow oxygen therapy seems to be ineffective in the acute phase of CS but may be a useful option in the weaning phase, as it allows shortening of invasive ventilation [35, 36]. Continuous positive airway pressure is a rather simple technique that could be helpful during pre-hospital treatment and in low-equipped units [35]. Noninvasive pressure support ventilation is considered to be the most effective technique of noninvasive ventilation [34,37], especially in patients with hypercapnia [38, 39].

As patients with respiratory failure are hemodynamically unstable, invasive ventilation is the most common therapeutic option in this population. Recently, the TRIUMPH study showed that a 1-hour delay in mechanical ventilation in patients with CS was associated with a significant increase in 30-day mortality [29].

The use of mechanical ventilation and moderate positive end-expiratory pressure (PEEP) levels helps achieve improved oxygenation and hemodynamic parameters in most patients with CS. However, caution should be exercised in patients with preload-dependent LV function, with right $\mathrm{Ml}$ or volume depletion. Preload optimization is also indicated in this population. A summary of PEEP ventilation according to the etiology of shock, along with an algorithm for PEEP use in patients with CS, are presented in Figure 1.

\section{COMPLICATIONS OF MECHANICAL CIRCULATORY SUPPORT}

The most severe complications of MCS include bleeding, thromboembolic events, and, to a lesser extent, infection and hemolysis. Currently, data from randomized controlled trials comparing different MCS devices are lacking. Therefore, it is impossible to determine which of the devices offers the greatest safety or, conversely, is associated with the highest risk of complications. Available registries and meta-analyses indicate that IABP counterpulsation is most often linked to the lowest number of complications. This 
refers to local complications related to vascular access, peripheral complications related to limb, central nervous system, renal, and intestinal ischemia, as well as systemic complications (infections) [10]. Impella implantation is associated with a similar or a slightly higher rate of local, peripheral, and systemic complications in comparison with IABP, while ECMO seems to have the highest complication rates (Table 10) [13, 40-50].

\section{Article information}

\section{Conflict of interest: None declared.}

Open access: This article is available in open access under Creative Common Attribution-Non-Commercial-No Derivatives 4.0 International (CC BY-NC-ND 4.0) license, allowing to download articles and share them with others as long as they credit the authors and the publisher, but without permission to change them in any way or use them commercially. For commercial use, please contact the journal office at kardiologiapolska@ptkardio.pl.

How to cite: Tycińska A, Grygier M, Biegus J, et al. Mechanical circulatory support. An expert opinion of the Association of Intensive Cardiac Care and Association of Cardiovascular Interventions of the Polish Cardiac Society. Kardiol Pol. 2021; 79(12): 1399-1410, doi: 10.33963/KP.a2021.0169.

\section{REFERENCES}

1. Collet JP, Thiele $H$, Barbato $E$, et al. Questions and answers on workup diagnosis and risk stratification: a companion document of the 2020 ESC Guidelines for the management of acute coronary syndromes in patients presenting without persistent ST-segment elevation. Eur Heart J. 2021; 42(14): 1379-1386, doi: 10.1093/eurheartj/ehaa602, indexed in Pubmed: 32860030.

2. McDonagh TA, Metra M, Adamo M, et al. 2021 ESC Guidelines for the diagnosis and treatment of acute and chronic heart failure. Eur Heart J. 2021; 42(36): 3599-3726, doi: 10.1093/eurheartj/ehab368, indexed in Pubmed: 34447992.

3. Tehrani BN, Truesdell AG, Psotka MA, et al. Standardized team-based care for cardiogenic shock. J Am Coll Cardiol. 2019; 73(13): 1659-1669, doi: 10.1016/j.jacc.2018.12.084, indexed in Pubmed: 30947919.

4. Kar B, Gregoric I, Basra S, et al. The percutaneous ventricular assist device in severe refractory cardiogenic shock. J Am Coll Cardiol. 2011; 57(6): 688-696, doi: 10.1016/j.jacc.2010.08.613, indexed in Pubmed: 20950980.

5. Chioncel O, Parissis J, Mebazaa A, et al. Epidemiology, pathophysiology and contemporary management of cardiogenic shock - a position statement from the Heart Failure Association of the European Society of Cardiology. Eur J Heart Fail. 2020; 22(8): 1315-1341, doi: 10.1002/ejhf.1922, indexed in Pubmed: 32469155.

6. Keebler ME, Haddad EV, Choi CW, et al. Venoarterial extracorporeal membrane oxygenation in cardiogenic shock. JACC Heart Fail. 2018;6(6): 503-516, doi: 10.1016/j.jchf.2017.11.017, indexed in Pubmed: 29655828.

7. Shin TG, Choi JH, Jo IkJ, et al. Extracorporeal cardiopulmonary resuscitation in patients with inhospital cardiac arrest: A comparison with conventional cardiopulmonary resuscitation. Crit Care Med. 2011; 39(1): 1-7, doi: 10.1097/CCM.0b013e3181feb339, indexed in Pubmed: 21057309.

8. Aso S, Matsui H, Fushimi K, et al. The effect of intraaortic balloon pumping under venoarterial extracorporeal membrane oxygenation on mortality of cardiogenic patients: an analysis using a nationwide inpatient database. Crit Care Med. 2016; 44(11): 1974-1979, doi: 10.1097/CCM.0000000000001828, indexed in Pubmed: 27322361.

9. Pappalardo F, Schulte C, Pieri M, et al. Concomitant implantation of Impella on top of veno-arterial extracorporeal membrane oxygenation may improve survival of patients with cardiogenic shock. Eur J Heart Fail. 2017; 19(3): 404-412, doi: 10.1002/ejhf.668, indexed in Pubmed: 27709750.

10. Rihal CS, Naidu SS, Givertz MM, et al. 2015 SCAI/ACC/HFSA/STS Clinical Expert Consensus Statement on the Use of Percutaneous Mechanical Circulatory Support Devices in Cardiovascular Care (Endorsed by the American Heart Association, the Cardiological Society of India, and Sociedad
Latino Americana de Cardiología Intervencionista; Affirmation of Value by the Canadian Association of Interventional Cardiology-Association Canadienne de Cardiologie d'intervention). Catheter Cardiovasc Interv. 2015; 85(7): 1112-1114, doi: 10.1002/ccd.25719, indexed in Pubmed: 25850944.

11. Clinical Study of Extra-Corporal Life Support in Cardiogenic Shock Complicating Acute Myocardial Infarction (ECLS-SHOCK). ClinicalTrials. gov Identifier: NCT02544594. Available online: https: //clinicaltrials. gov/ct2/show/NCT02544594.

12. Bass TA. High-Risk percutaneous coronary interventions in modern day clinical practice: current concepts and challenges. Circ Cardiovasc Interv. 2015; 8(12): e003405, doi: 10.1161/CIRCINTERVENTIONS.115.003405, indexed in Pubmed: 26628592.

13. Thiele H, Zeymer U, Neumann FJ, et al. Intraaortic balloon support for myocardial infarction with cardiogenic shock. NEngl J Med. 2012; 367(14): 1287-1296, doi: 10.1056/nejmoa1208410, indexed in Pubmed: 22920912.

14. Strom JB, Zhao $Y$, Shen $C$, et al. National trends, predictors of use, and in-hospital outcomes in mechanical circulatory support for cardiogenic shock. Eurolntervention. 2018; 13(18): e2152-e2159, doi: 10.4244/EIJ-D-17-00947, indexed in Pubmed: 29400657.

15. Patel SM, Lipinski J, Al-Kindi SG, et al. Simultaneous venoarterial extracorporeal membrane oxygenation and percutaneous left ventricular decompression therapy with impella is associated with improved outcomes in refractory cardiogenic shock. ASAIO J. 2019; 65(1): 21-28, doi: 10.1097/MAT.0000000000000767, indexed in Pubmed: 29489461.

16. Guglin M, Zucker MJ, Bazan VM, et al. Venoarterial ECMO for adults: JACC Scientific Expert Panel. J Am Coll Cardiol. 2019; 73(6): 698-716, doi: 10.1016/j.jacc.2018.11.038, indexed in Pubmed: 30765037.

17. Chen YS, Lin JW, Yu HY, et al. Cardiopulmonary resuscitation with assisted extracorporeal life-support versus conventional cardiopulmonary resuscitation in adults with in-hospital cardiac arrest: an observational study and propensity analysis. Lancet. 2008; 372(9638): 554-561, doi: 10.1016/S0140-6736(08)60958-7, indexed in Pubmed: 18603291.

18. Abrams D, Garan AR, Abdelbary A, et al. Position paper for the organization of ECMO programs for cardiac failure in adults. Intensive Care Med. 2018; 44(6): 717-729, doi: 10.1007/s00134-018-5064-5, indexed in Pubmed: 29450594.

19. Desai SR, Hwang NC. Strategies for left ventricular decompression during venoarterial extracorporeal membrane oxygenation - a narrative review. J Cardiothorac Vasc Anesth. 2020; 34(1): 208-218, doi: 10.1053/j. jvca.2019.08.024, indexed in Pubmed: 31530454.

20. Pineton de Chambrun $M$, Bréchot N, Combes A. Mechanical circulatory devices in acute heart failure. Curr Opin Crit Care. 2018; 24(4): 286-291, doi: 10.1097/MCC.0000000000000520, indexed in Pubmed: 29901460.

21. Kenaan M, Gajera M, Goonewardena SN. Hemodynamic assessment in the contemporary intensive care unit: a review of circulatory monitoring devices. Crit Care Clin. 2014; 30(3):413-445, doi: 10.1016/j.ccc.2014.03.007, indexed in Pubmed: 24996604.

22. Kirton OC, Calabrese RC, Staff I. Increasing use of less-invasive hemodynamic monitoring in 3 specialty surgical intensive care units: a 5 -year experience at a tertiary medical center. J Intensive Care Med. 2015; 30(1): 30-36, doi: 10.1177/0885066613498055, indexed in Pubmed: 23940109.

23. Chatterjee K. The Swan-Ganz catheters: past, present, and future. A viewpoint. Circulation. 2009; 119(1): 147-152, doi: 10.1161/CIRCULATIONAHA.108.811141, indexed in Pubmed: 19124674.

24. Vincent JL, Rhodes A, Perel A, et al. Clinical review: Update on hemodynamic monitoring--a consensus of 16. Crit Care. 2011; 15(4): 229, doi: 10.1186/cc10291, indexed in Pubmed: 21884645.

25. Seymour CW, Liu VX, Iwashyna TJ, et al. Assessment of clinical criteria for sepsis: for the third international consensus definitions for sepsis and septic shock (sepsis-3). JAMA. 2016; 315(8): 762-774, doi: 10.1001/jama.2016.0288, indexed in Pubmed: 26903335.

26. Sorajja P, Borlaug BA, Dimas V, et al. Executive summary of the SCAI/HFSA clinical expert consensus document on the use of invasive hemodynamics for the diagnosis and management of cardiovascular disease. Catheter Cardiovasc Interv. 2017; 89(7): 1294-1299, doi: 10.1002/ccd.27036, indexed in Pubmed: 28489324.

27. Binanay C, Califf RM, Hasselblad V, et al. Evaluation study of congestive heart failure and pulmonary artery catheterization effectiveness: the ESCAPE trial. JAMA. 2005; 294(13): 1625-1633, doi: 10.1001/jama.294.13.1625, indexed in Pubmed: 16204662. 
28. Cecconi M, De Backer D, Antonelli M, et al. Consensus on circulatory shock and hemodynamic monitoring. Task force of the European Society of Intensive Care Medicine. Intensive Care Med. 2014; 40(12): 1795-1815, doi: 10.1007/s00134-014-3525-z, indexed in Pubmed: 25392034.

29. van Diepen S, Hochman JS, Stebbins A, et al. Association between delays in mechanical ventilation initiation and mortality in patients with refractory cardiogenic shock. JAMA Cardiol. 2020; 5(8): 965-967, doi: 10.1001/jamacardio.2020.1274, indexed in Pubmed: 32432650.

30. Gordon AC, Wang N, Walley KR, et al. The cardiopulmonary effects of vasopressin compared with norepinephrine in septic shock. Chest. 2012; 142(3): 593-605, doi: 10.1378/chest.11-2604, indexed in Pubmed: 22518026.

31. Wada Y, Aiba T, Tsujita Y, et al. Practical applicability of landiolol, an ultra-short-acting $\beta 1$-selective blocker, for rapid atrial and ventricular tachyarrhythmias with left ventricular dysfunction. J Arrhythm. 2016; 32(2): 82-88, doi: 10.1016/j.joa.2015.09.002, indexed in Pubmed: 27092187.

32. Kouraki K, Schneider S, Uebis R, et al. Characteristics and clinical outcome of 458 patients with acute myocardial infarction requiring mechanical ventilation. Results of the BEAT registry of the ALKK-study group. Clin Res Cardiol. 2011;100(3):235-239, doi: 10.1007/s00392-010-0235-6, indexed in Pubmed: 20878411.

33. Drakos SG, Bonios MJ, Anastasiou-Nana MI, et al. Long-term survival and outcomes after hospitalization for acute myocardial infarction complicated by cardiogenic shock. Clin Cardiol. 2009; 32(8): E4-E8, doi: 10.1002/clc.20488, indexed in Pubmed: 19455673.

34. Hongisto M, Lassus J, Tarvasmaki T, et al. Use of noninvasive and invasive mechanical ventilation in cardiogenic shock: A prospective multicenter study. Int J Cardiol. 2017; 230: 191-197, doi: 10.1016/j.ijcard.2016.12.175, indexed in Pubmed: 28043661.

35. Makdee O, Monsomboon A, Surabenjawong U, et al. High-Flow nasal cannula versus conventional oxygen therapy in emergency department patients with cardiogenic pulmonary edema: a randomized controlled trial. Ann Emerg Med. 2017; 70(4): 465-472.e2, doi: 10.1016/j.annemergmed.2017.03.028, indexed in Pubmed: 28601264.

36. Masip J, Peacock WF, Price $S$, et al. Indications and practical approach to non-invasive ventilation in acute heart failure. Eur Heart J. 2018; 39(1): 17-25, doi: 10.1093/eurheartj/ehx580, indexed in Pubmed: 29186485.

37. Nouira S, Boukef R, Bouida W, et al. Non-invasive pressure support ventilation and CPAP in cardiogenic pulmonary edema: a multicenter randomized study in the emergency department. Intensive Care Med. 2011; 37(2): 249-256, doi: 10.1007/s00134-010-2082-3, indexed in Pubmed: 21136039

38. Masip J, Betbesé AJ, Páez J, et al. Non-invasive pressure support ventilation versus conventional oxygen therapy in acute cardiogenic pulmonary oedema: a randomised trial. Lancet. 2000; 356(9248): 2126-2132, doi: 10.1016/s0140-6736(00)03492-9, indexed in Pubmed: 11191538.

39. Nava S, Carbone G, DiBattista N, et al. Noninvasive ventilation in cardiogenic pulmonary edema: a multicenter randomized trial. Am J Respir Crit
Care Med. 2003; 168(12): 1432-1437, doi: 10.1164/rccm.200211-12700C, indexed in Pubmed: 12958051

40. Enezate T, Eniezat M, Thomas J. Utilization and outcomes of temporary mechanical circulatory support devices in cardiogenic shock. Am J Cardiol. 2019; 124(4): 505-510, doi: 10.1016/j.amjcard.2019.05.032, indexed in Pubmed: 31204034.

41. Cheng JM, den Uil CA, Hoeks SE, et al. Percutaneous left ventricular assist devices vs. intra-aortic balloon pump counterpulsation for treatment of cardiogenic shock: a meta-analysis of controlled trials. Eur Heart J. 2009; 30(17): 2102-2108, doi: 10.1093/eurheartj/ehp292, indexed in Pubmed: 19617601.

42. Al-Khadra Y, Alraies MC, Darmoch F, et al. Outcomes of nonemergent percutaneous coronary intervention requiring mechanical circulatory support in patients without cardiogenic shock. Catheter Cardiovasc Interv. 2020; 95(3): 503-512, doi: 10.1002/ccd.28383, indexed in Pubmed: 31254325.

43. Schrage B, Ibrahim K, Loehn T, et al. Impella support for acute myocardial infarction complicated by cardiogenic shock. Circulation. 2019; 139(10): 1249-1258, doi: 10.1161/CIRCULATIONAHA.118.036614, indexed in Pubmed: 30586755.

44. Lauten $A$, Engström AE, Jung C, et al. Percutaneous left-ventricular support with the Impella-2.5-assist device in acute cardiogenic shock: results of the Impella-EUROSHOCK-registry. Circ Heart Fail. 2013; 6(1): 23-30, doi: 10.1161/CIRCHEARTFAILURE.112.967224, indexed in Pubmed: 23212552.

45. Burzotta F, Trani C, Doshi SN, et al. Impella ventricular support in clinical practice: Collaborative viewpoint from a European expert user group. Int J Cardiol. 2015; 201: 684-691, doi: 10.1016/j.ijcard.2015.07.065, indexed in Pubmed: 26363632.

46. Thiele H, Zeymer U, Neumann FJ, et al. Intra-aortic balloon counterpulsation in acute myocardial infarction complicated by cardiogenic shock (IABP-SHOCK II): final 12 month results of a randomised, open-label trial. Lancet. 2013;382(9905): 1638-1645, doi: 10.1016/s0140-6736(13)61783-3.

47. Bonicolini E, Martucci G, Simons J, et al. Limb ischemia in peripheral veno-arterial extracorporeal membrane oxygenation: a narrative review of incidence, prevention, monitoring, and treatment. Crit Care. 2019;23(1): 266, doi: 10.1186/s13054-019-2541-3, indexed in Pubmed: 31362770.

48. Burrell AJC, Bennett V, Serra AL, et al. Venoarterial extracorporeal membrane oxygenation: A systematic review of selection criteria, outcome measures and definitions of complications. J Crit Care. 2019; 53: 32-37, doi: 10.1016/j.jcrc.2019.05.011, indexed in Pubmed: 31181462.

49. Renaudier $M$, de Roux $Q$, Bougouin W, et al. Acute mesenteric ischaemia in refractory shock on veno-arterial extracorporeal membrane oxygenation. Eur Heart J Acute Cardiovasc Care. 2020; 10(1): 62-70, doi: 10.1177/2048872620915655, indexed in Pubmed: 33609105.

50. Appelt $\mathrm{H}$, Philipp A, Mueller $\mathrm{T}$, et al. Factors associated with hemolysis during extracorporeal membrane oxygenation (ECMO)-Comparison of VA-versus VV ECMO. PLoS One. 2020; 15(1): e0227793, doi: 10.1371/journal.pone.0227793, indexed in Pubmed: 31986168. 